\title{
A Novel Hybrid Clamped Three-level Converter
}

\author{
Yue Yuntao ${ }^{1.2}$ Qiu Kekun ${ }^{1}$ Lin Yan ${ }^{2}$ \\ (1. Beijing University Of Civil Engineering And Architecture BeiJing 100044, \\ China 2.Beijing University of Aeronautics and Astronautics, Beijing 100083, \\ China) \\ yueyuntao@bucea.edu.cn
}

\begin{abstract}
A novel hybrid clamped dual-PWM three-level converter topology is proposed for induction motor drives in this paper. The switching states of hybrid clamp three-level converters increase to sixty-four from twenty-seven switching states of diode clamp threelevel converters. In order to realize optimization of its redundant voltage space vectors by detecting voltage of clamp capacitor and difference of capacitor voltage in DC side, Generating an optimized switching pattern, The hybrid clamped three-level converter increases the voltage levels number, reducing the harmonics associated to the commutation frequency and limiting the $d v / d t$ by all the switches. It can quickly balance the DC voltage, Realized system of 4-Quardant Running. the control circuit and main circuit was designed with DSP and CPLD, experimentation results proved it is very effective and practicability.
\end{abstract}

Keywords: Dual-PWM, Three Level Converter, Hybrid Clamped, Voltage Space Vector

\section{Introduction}

In recent years, multilevel converters has been widely studied for high power and medium voltage applications because of their advantages of low voltage stress for power semiconductors, low voltage harmonics and less electromagnetic interference. Many topologies and modulation strategies have been proposed and researched extensively for utility and drive applications [1-6], such as active power filters, static VAR compensators, and high voltage motor drives due to their ability to obtain waveforms with better harmonic spectrum and achieve higher voltages with a lower maximum device rating, The output waveforms of the multilevel converters are smoother than those of a two-level converters as the output voltage is synthesized from multiple levels of dc voltage. The topologies of multilevel converters can be classified into neutral-diode-clamp (NPC) converter, capacitorclamped converter and series-connected H-bridge converter. NPC topologies have been proposed and successfully used in high-power motor drive and utility applications, The advantages of the NPC converters are the improvement of waveform devices, It is very difficult to keep the upper and lower DC-link capacitor voltages balanced to guarantee the multilevel operation of the converter[7-10]. Capacitor-clamped topologies were proposed for high-voltage motor and active power filters, The capacitor- clamped converter is an alternative structure used to obtain multi-level waveforms on the AC terminals, The flying capacitor multilevel converter does not require isolated DC sides and additional clamping diodes, Snubberless operation is possible and easy to expand to multilevel. However, It is serious problem to be quite limited by the voltage unbalancing of flying capacitors [11-16]. Series connection of H-bridge converter is an alternative method of achieving multilevel waveforms because of their modularity and simplicity of 
control, the H-bridge cascade converter has been used in several practical instance for broadcasting amplifier, plasma, industrial drive as well as STATCOM applications [17-19], The main limitation of the H-bridge cascade converter consists in the provision of an isolated power supply for each individual $\mathrm{H}$-bridge cell when real power transfer is demanded. Hybrid multilevel converters with different switching frequencies were proposed in [18], however, the disadvantage of multilevel converters is that many power devices require to be used in the circuits. If the voltage level is more than five, the implementation of control strategy is complicated [21].

Pulse Width Modulation (PWM) for AC drives has been studied extensively during the past decades. Many different PWM methods have been developed to achieve the following aims: wide linear modulation range; less switching loss; less total harmonic distortion (THD) in the spectrum of switching waveforms; and easy implementation as well as less computation time. For a long period, carrier-based PWM methods were widely used in most applications [20]. The earliest modulation signals for carrier-based PWM are sinusoidal. The use of an injected zero-sequence signal for a three phase inverters initiated the research on nonsinusoidal carrierbased PWM. With the development of microprocessors, in recent years, Space Vector Modulation (SVM) has become one of the most important PWM methods for three phase converters. It uses the space vector concept to compute the duty cycle of the switches. It is simply the digital implementation of PWM modulators. An aptitude for easy digital implementation and wide linear modulation range for output line-to-line voltages are the notable features of space vector modulation. However, the implementation of conventional SVPWM is not an easy work even being based on DSP. With the help of lookup Table, computation of DSP could be simplified. But, lookup Table tends to give reduced pulse width resolution unless it is very large [23]. In recent years, many attempts have been made to unite the two types of PWM methods [31-32], because the comprehensive relation of the two types of PWM methods will provide a platform not only to transform from one to another, but also to develop different performance PWM modulation[24]. Another interesting research subject for SVPWM has been focusing on the simplification of SVPWM on line computation that has very important significance for real implementation in industry.

In this paper, we proposed a novel hybrid clamped dual-PWM three-level circuit topology for induction motor drives. The principle of the hybrid clamped circuit topology is discussed in detail, the switching states of hybrid clamp three-level converters increase to sixty-four from twenty-seven switching states of diode clamp three-level converters. Generating an optimized switching pattern of its redundant voltage space vectors by detecting voltage of clamp capacitor and difference of capacitor voltage in DC side, reducing the harmonics associated to the commutation frequency and limiting the $\mathrm{dv} / \mathrm{dt}$ by all the switches. The control circuit and main circuit was designed with DSP and CPLD, experimentation results proved it is very effective and practicability.

\section{Hybrid Model Reference Adaptive System}

The Figure 1 shows a new multilevel converter topology in this paper, Note that there are the inner clamping capacitor which is not found in a conventional multilevel converter structure. It is DC-link voltage sources that supply power to the loads. The branch diodes are connected to the neutral point "o" of de capacitors. switching states of each phase of the converter are listed in Table 1. 
Table 1. Switching States Of Hybrid Clamped Topology and Output Level (As A Phase)

\begin{tabular}{|c|c|c|c|c|}
\hline $\begin{array}{c}\text { Output } \\
\text { voltage }\end{array}$ & $\mathrm{S}_{\mathrm{a} 1}$ & $\mathrm{~S}_{\mathrm{a} 2}$ & $\mathrm{~S}_{\mathrm{a} 3}$ & $\mathrm{~S}_{\mathrm{a} 4}$ \\
\hline $\mathrm{p}$ & on & on & off & off \\
\hline $\mathrm{oA}$ & off & on & off & on \\
\hline $\mathrm{oB}$ & on & off & on & off \\
\hline $\mathrm{n}$ & off & off & on & on \\
\hline
\end{tabular}

At each switching mode, there are four equivalent circuit of output state in this topologies,

The current paths are formed as following:

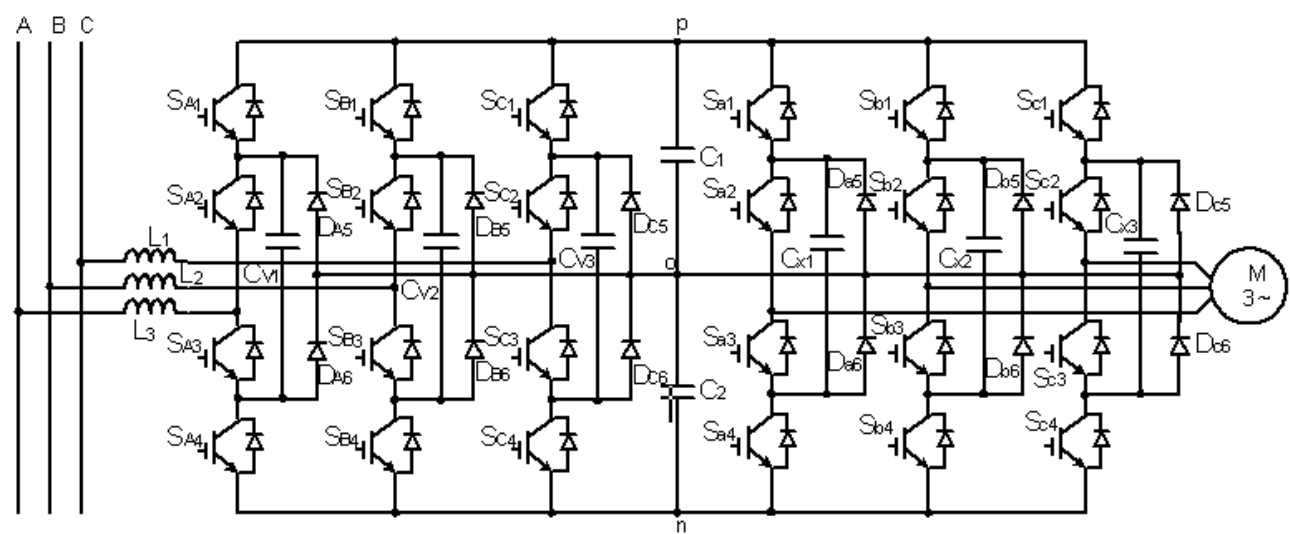

Figure 1. The Topology of Hybrid Clamp Three Level Three Phase Converter

1) p vector: the operating principle is shown in Figure 2, output voltage becomes $V_{\mathrm{dc}} / 2$ through $\mathrm{S}_{\mathrm{a} 1}-\mathrm{S}_{\mathrm{a} 2}$ turned on and a bidirectional current path for ac load is achieved through freewheeling diode $D_{1}-D_{2}$, as shown by solid paths. That is process of $p$ vector, If the voltage of capacitor $\mathrm{C}_{\mathrm{x} 1}$ is lower than $\mathrm{V}_{\mathrm{dc}} / 2$, it will be charged to $\mathrm{V}_{\mathrm{dc}} / 2$ by discharging capacitor $\mathrm{C}_{\mathrm{d} 1}$, as shown by dotted path (1). On the contrary, if the voltage of $\mathrm{C}_{\mathrm{x} 1}$ is higher than $\mathrm{V}_{\mathrm{dc}} / 2$, the voltage of $\mathrm{C}_{\mathrm{x} 1}$ will not be changed and discharged to $\mathrm{V}_{\mathrm{dc}} / 2$ along with the load current in next switching period.

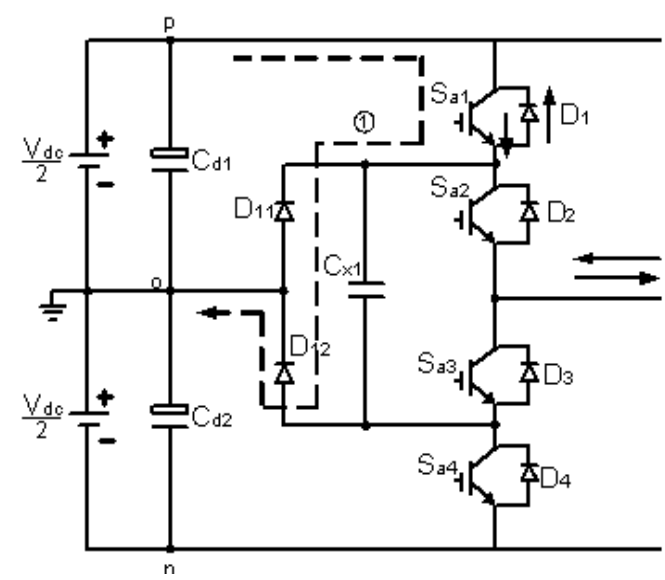

Figure 2. P Vector Current Circuit 


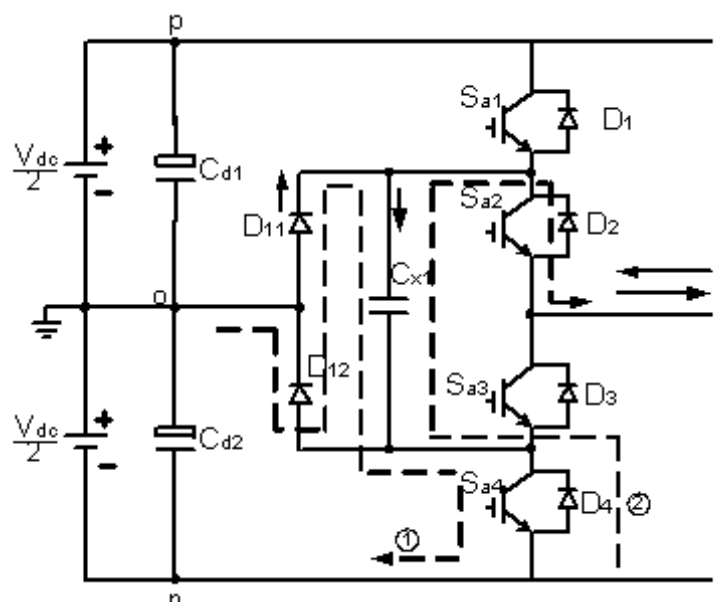

Figure 3. oA Vector Current Circuit

2) oA vector: current paths are shown in Figure 3, the switching $S_{\mathrm{a} 2}$ and $S_{\mathrm{a} 4}$ are turned on, $S_{\mathrm{a} 1}$ and $\mathrm{S}_{\mathrm{a} 3}$ are turned off in the whole process. Output voltage zero is formed by the capacitor $\mathrm{C}_{\mathrm{d} 2}$ voltage that is discharged through branch diode $\mathrm{D}_{11}$ and $\mathrm{S}_{\mathrm{a} 2}$, and a bidirectional current path for ac load is $D_{2} 、 C_{x 1}$ and $S_{a 4}$, as shown by solid paths. That is process of oA vector, If the voltage of capacitor $\mathrm{C}_{\mathrm{x} 1}$ is lower than $\mathrm{V}_{\mathrm{dc}} / 2$, it will be charged to $V_{d c} / 2$ by current path of $D_{11}-C_{x 1}-S_{a 4}$, as shown by dotted path (1). On the contrary, if the voltage of $\mathrm{C}_{\mathrm{x} 1}$ is higher than $\mathrm{V}_{\mathrm{dc}} / 2$, the voltage of $\mathrm{C}_{\mathrm{x} 1}$ will be discharged along with current path of $\mathrm{D}_{4}-\mathrm{C}_{\mathrm{x} 1}-\mathrm{S}_{\mathrm{a} 2}$. as shown by dotted paths (2). It will decrease waving amplitude of DC capacitor voltage when required output voltage is obtained.

3) $\mathrm{oB}$ vector: current paths of oB vector are shown in Figure 5, the switching $S_{\mathrm{a} 1}$ and $S_{\mathrm{a} 3}$ are turned on, $S_{\mathrm{a} 2}$ and $S_{\mathrm{a} 4}$ are turned off in the whole process. Output voltage zero is achieved through a current path $\mathrm{C}_{\mathrm{d} 2}-\mathrm{C}_{\mathrm{d} 1}-\mathrm{S}_{\mathrm{a} 1}-\mathrm{C}_{\mathrm{x} 1}-\mathrm{D}_{3}$, and a bidirectional current path for ac load is $\mathrm{S}_{\mathrm{a} 3}-\mathrm{D}_{12}-\mathrm{C}_{\mathrm{d} 2}$, as shown by solid paths. If the voltage of capacitor $\mathrm{C}_{\mathrm{x} 1}$ is lower than $\mathrm{V}_{\mathrm{dc}} / 2$, it will be charged to $\mathrm{V}_{\mathrm{dc}} / 2$ by current path of $\mathrm{S}_{\mathrm{a} 1}-\mathrm{C}_{\mathrm{x1}}-\mathrm{D}_{12}$, as shown by dotted path (1). On the contrary, if the voltage of $C_{x 1}$ is higher than $V_{d c} / 2$, the voltage of $C_{x 1}$ will not be changed and discharged to $\mathrm{V}_{\mathrm{dc}} / 2$ along with the load current in next switching period.

4) $n$ vector: current paths of $n$ vector are shown in Figure 6, the switching $S_{a 3}$ and $S_{a 4}$ are turned on, $S_{\mathrm{a} 1}$ and $\mathrm{S}_{\mathrm{a} 3}$ are turned off in the whole process. Output voltage is $-\mathrm{V}_{\mathrm{dc}} / 2$ and $\mathrm{D}_{3}-\mathrm{D}_{4}$ forms bidirectional current path, as shown by solid paths, If the voltage of capacitor $\mathrm{C}_{\mathrm{x} 1}$ is lower than $\mathrm{V}_{\mathrm{dc}} / 2$, it will be charged to $\mathrm{V}_{\mathrm{dc}} / 2$ by current path of $\mathrm{D}_{11} \mathrm{C}_{\mathrm{x} 1^{-}}$ $\mathrm{S}_{\mathrm{a} 4}$, as shown by dotted path (1). On the contrary, if the voltage of $\mathrm{C}_{\mathrm{x} 1}$ is higher than $\mathrm{V}_{\mathrm{dc}} / 2$, the voltage of $\mathrm{C}_{\mathrm{x} 1}$ will not be changed and discharged to $\mathrm{V}_{\mathrm{dc}} / 2$ along with the load current in next switching period. 


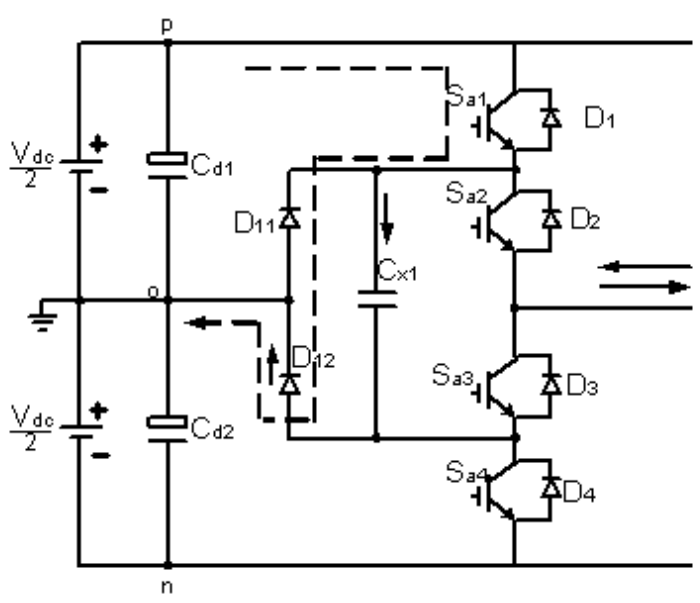

Figure 4. oB Vector Current Circuit

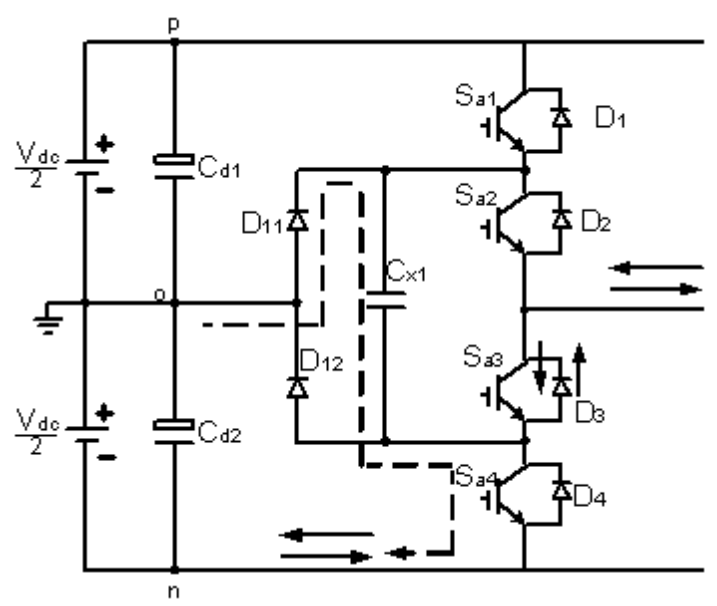

Figure 5. n Vector Current Circuit

From Figure 2-5, we can see that the voltage $\mathrm{C}_{\mathrm{x} 1}$ charged to the voltage $\mathrm{V}_{\mathrm{dc}} / 2$ at the beginning can always be kept to $\mathrm{V}_{\mathrm{dc}} / 2$ by charging or discharging action with $\mathrm{C}_{\mathrm{d} 1}$ and $\mathrm{C}_{\mathrm{d} 2}$, Bidirectional current is achieved through $\mathrm{C}_{\mathrm{x} 1}$, It is added a clamp capacitor in each bridge, this capacitor clamped the voltage when the switch is turned off. It can reduce unbalance of DC capacitor by proceed of capacitor charged and discharged. Clamp capacitor can realize bidirectional flow; The flexibility of vector synthesize is increased because of increased switching state, The switching states of hybrid clamp three-level converters is increased to sixty-four from twentyseven switching states of diode clamp three-level converters, It can realize the more complicated and more accurate control, The operational principle of rectifier is similar.

\section{Voltage Space Vector PWM Algorithm}

\subsection{Review of SVPWM in Undermodulation}

Figure 6 explains SVPWM operation in the undermodulation and overmodulation regions, The operation in undermodulation or overmodulation is determined by the modulation factor, which is defined as:

$$
m=\frac{V^{*}}{V_{1 s w}}(1)
$$


where $V^{\text {" }}$ is the magnitude of command or reference voltage vector and $V_{1 s w}$ is the fundamental peak value $\left(2 V_{d} / \pi\right)$ of the square (or six step) phase voltage wave [26].

In the undermodulation as shown in Figure 6(a), $0<\mathrm{m}<0.907$. In overmodulation Mode-1 as shown in Figure 6(b), 0.907 $<\mathrm{m}<0.9514$. In overmodulation Mode-2 as explained in Figure 6(c), $0.9514<\mathrm{m}<1.0$.
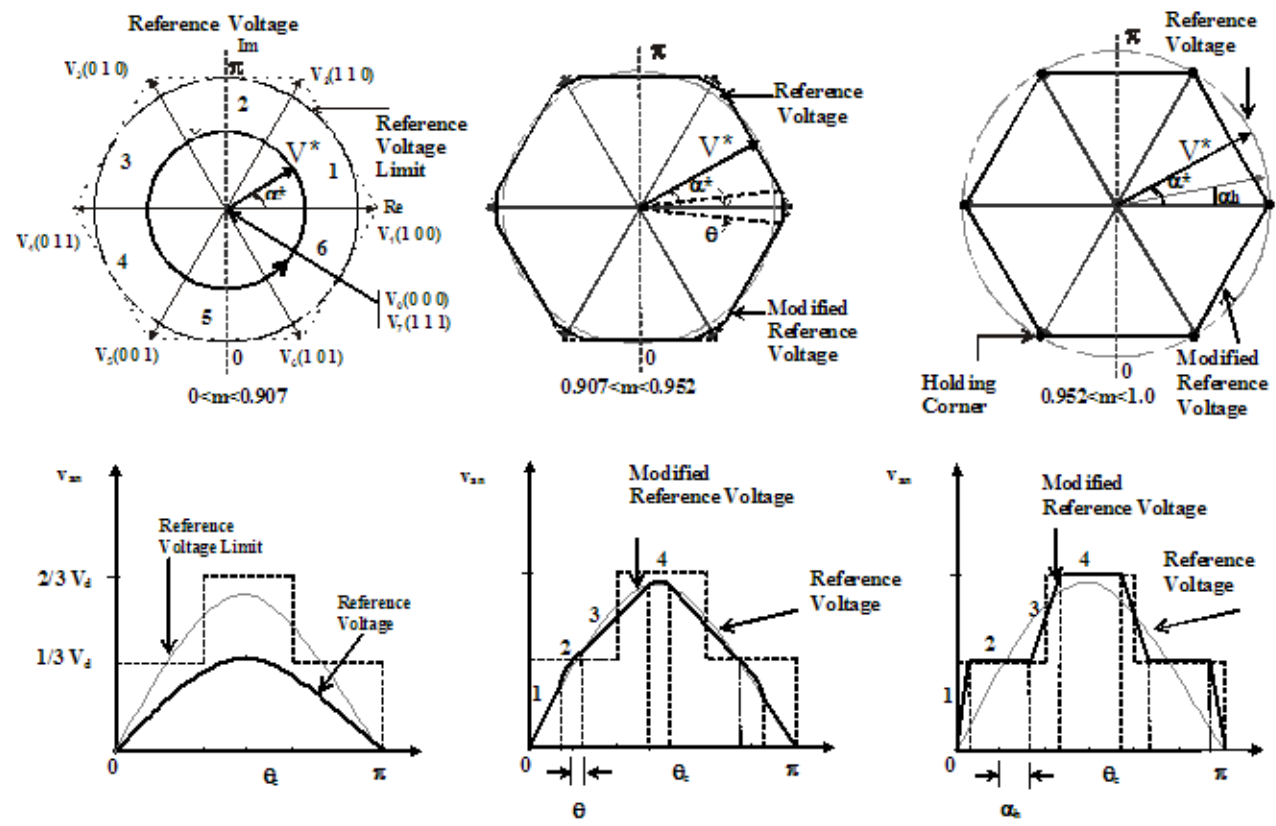

(a) Undermodulation

(b) Overmodulation Mode-1

(c) Overmodulation Mode-2

\section{Figure 6. Voltage Trajectories in Undermodulation and Overmodulation Regions and the Corresponding Phase Voltage}

\subsection{Review of SVPWM in Undermodulation}

Figure 7 shows the three reference sinusoidal command voltages in naturally sampled SPWM. It has been proved that when a kind of zero sequence component is added to the sinusoidal reference waveform as listed in Table 2, The naturally sampled SPWM will become naturally sampled SVPWM with exactly the same output voltage as that of the conventional SVPWM [22-24].

Table 2. Zero Sequence Components

\begin{tabular}{|l|l|l|l|l|l|l|l|}
\hline$\omega t$ & $0 \sim \frac{\pi}{6}$ & $\frac{\pi}{6} \sim \frac{\pi}{2}$ & $\frac{\pi}{2} \sim \frac{5 \pi}{6}$ & $\frac{5 \pi}{6} \sim \frac{7 \pi}{6}$ & $\frac{7 \pi}{6} \sim \frac{3 \pi}{2}$ & $\frac{3 \pi}{2} \sim \frac{11 \pi}{6}$ & $\frac{11 \pi}{6} \sim 2 \pi$ \\
\hline$v_{0}$ & $v_{a}^{*} / 2$ & $v_{b}^{*} / 2$ & $v_{c}^{*} / 2$ & $v_{a}^{*} / 2$ & $v_{b}^{*} / 2$ & $v_{c}^{*} / 2$ & $v_{a}^{*} / 2$ \\
\hline
\end{tabular}

Figure 8 shows the corresponding three pole command voltages $v_{a o}^{*}, v_{b o}^{*}, v_{c o}^{*}$ in naturally sampled SVPWM.

When pole command voltage $v_{x o}^{*}$ (x stands for a,b or c) reaches to $0.5 V_{d}$ (limit of undermodulation), the peak value of line-to-neutral phase command voltage $v_{x n}^{*}$ will be: $V^{*}=V_{d} / \sqrt{3}$, so, the maximum modulation factor that naturally sampled SVPWM in undermodulation can achieve will be: 


$$
m_{\max }=\frac{V_{d} / \sqrt{3}}{2 V_{d} / \pi}=0.907
$$

If the magnitude of reference voltage $v_{x o}^{*}$ increase further, peak value will exceed $0.5 V_{d}$, then, inverter will be working in overmodulation region.

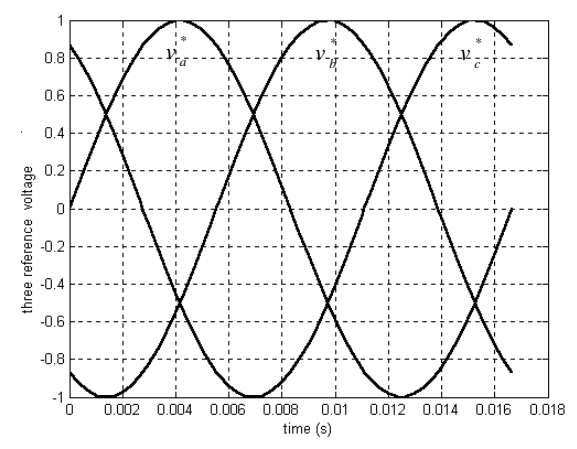

Figure 7. Waveform of Three Reference Voltages of Naturally Sampled SPWM

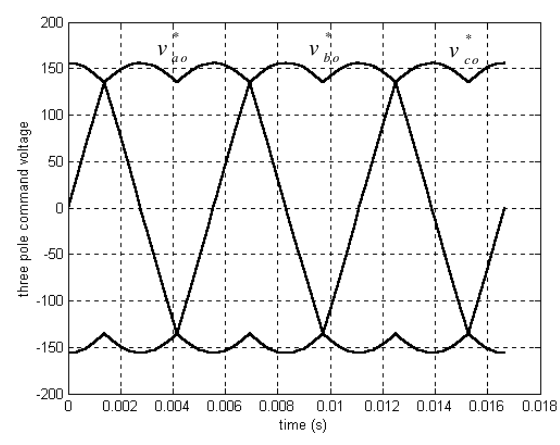

\section{Figure 8. Waveform of Three Pole Command Voltages of Naturally Sampled}

\subsection{The Novel SVPWM Algorithm}

Table 3 shows the summary of selected switching sequence of phase voltage for all the regions in the six sectors. Note that the sequence in opposite sectors is selected to be of a complimentary neutral-point voltage balancing. Voltage vectors switching states of each phase shows in Table 3. There are three switching states for the zero voltage vector $V_{0}$ and two switching states for the middle voltage vectors corresponding to the apexes of the smaller hexagon $\left(V_{1}, V_{4}, V_{7}, V_{10}, V_{13}, V_{16}\right)$ and one switching states for the large voltage $\operatorname{vectors}\left(V_{2}, \quad V_{3}, \quad V_{5}, \quad V_{6}, \quad V_{8}, \quad V_{9}, \quad V_{11}, V_{12}, \quad V_{14}, V_{15}, V_{17}, V_{18}\right)$. The middle voltage vectors $V_{1 p}$ and $V_{4 p}$ is concerned with charging or discharging of upper DC capacitor $C_{d 1}$ in Figure 1, on the other hand, the voltage vector $V_{1 n}$ and $V_{4 n}$ are concerned with charging or discharging of the lower DC capacitor $C_{d 2}$.

Figure 9 shows the voltage space vector representation of hybrid clamped three-level converter, Figure 10 shows the vector A triangle formed by the voltage vectors $V_{0} 、 V_{2}$ and $V_{5}$, this triangle can be divided into four smaller triangles $1,2,3,4$. The apexes of these smaller triangles correspond to the voltage vectors in Table 1. In the space vector PWM technique, generally three voltage vectors corresponding to the apexes of the triangle which includes the reference voltage vector are selected in order to minimize the 
harmonic components of the output line-to-line voltage. Duration of these three voltage vectors is obtained as follows.

Table 3. Three Level Vector Table of Hybrid Clamped Converter

\begin{tabular}{lc}
\hline Vector type & Voltage vector \\
\hline Large vector & PPN, PNN, PNP, NNP, NPP, NPN \\
Middle vector & PAN, PBN, PNA, PNB, ANP, BNP, NAP, NBP, NPA, NPB, APN, BPN \\
Small vector & PPA, PPB, ABN, BBN, BAN, AAA, PAA, PAB, PBB, PBA, ANN,BNN \\
& PAP, PBP, BNA, BNB, ANA, ANB, NNA, NNB, AAP, ABP, BAP, BBP \\
Zero vector & PPP, NNN, AAA, AAB, ABA, ABB, BAA, BAB, BBA, BBB \\
\hline
\end{tabular}

Table 4. Voltage Vectors Switching States Of Hybrid Clamped $(()=$ Switching Mode, $Y=A, B)$

\begin{tabular}{|c|c|c|c|c|}
\hline \multicolumn{2}{|c|}{ Voltage $\vec{V}_{\text {Vector }}^{*}$} & A phase & B phase & $\mathrm{C}$ phase \\
\hline \multirow{3}{*}{$\mathrm{V}_{0}$} & $\mathrm{~V}_{0 \mathrm{n}}$ & $-E / 2$ & $-E / 2$ & $-E / 2$ \\
\hline & $\mathrm{V}_{00}$ & $0(2 y)$ & $0(2 y)$ & $0(2 y)$ \\
\hline & $\mathrm{V}_{\mathrm{Op}}$ & $\mathrm{E} / 2$ & $E / 2$ & $\mathrm{E} / 2$ \\
\hline \multirow{2}{*}{$\mathrm{V}_{1}$} & $\mathrm{~V}_{1 \mathrm{n}}$ & $0(2 \mathrm{~A})$ & $-E / 2$ & $-E / 2$ \\
\hline & $\mathrm{V}_{1 \mathrm{p}}$ & $\mathrm{E} / 2$ & $0(2 \mathrm{~B})$ & $0(2 \mathrm{~B})$ \\
\hline \multicolumn{2}{|c|}{$\mathrm{V}_{2}$} & $\mathrm{E} / 2$ & $-\mathrm{E} / 2$ & $-E / 2$ \\
\hline \multicolumn{2}{|c|}{$\mathrm{V}_{3}$} & $\mathrm{E} / 2$ & $0(2 \mathrm{~A})$ & $-E / 2$ \\
\hline \multirow{2}{*}{$\mathrm{V}_{4}$} & $\mathrm{~V}_{4 \mathrm{n}}$ & $0(2 \mathrm{~A})$ & $0(2 \mathrm{~A})$ & $-E / 2$ \\
\hline & $\mathrm{V}_{4 \mathrm{p}}$ & $\mathrm{E} / 2$ & $\mathrm{E} / 2$ & $0(2 \mathrm{~B})$ \\
\hline \multicolumn{2}{|c|}{$\mathrm{V}_{5}$} & $\mathrm{E} / 2$ & $\mathrm{E} / 2$ & $-E / 2$ \\
\hline
\end{tabular}

For example, if the reference voltage vector $\mathrm{V}^{*}$ falls into the triangle $\mathrm{A}$, the duration of the voltage vectors Vo, VI and V4 which correspond to the apexes of the triangle A can be calculated by the following equations.

$$
V_{1} \cdot t_{a}+V_{3} \cdot t_{b}+V_{4} \cdot t_{c}=V^{*} \cdot T \quad t_{a}+t_{b}+t_{c}=T
$$


Table 5. Analytical Time Expressions of Voltage Vectors in Six Different Regions and Sectors

\begin{tabular}{|c|c|c|c|c|}
\hline sector & & $t_{a}$ & $t_{b}$ & $t_{c}$ \\
\hline \multirow{4}{*}{$A$} & 1 & $2 k \pi \sin (\pi / 3-\theta)$ & $T[:-2 k \sin (\theta+\pi / 3)]$ & $2 k T \sin \theta$ \\
\hline & 2 & $2 T[1-k \sin (\theta+\pi / 3)]$ & $2 k T \sin \theta$ & $T[2 k \sin (\pi / 3-\theta)-\vdots]$ \\
\hline & 3 & $T[1-2 k \sin \theta]$ & $T[2 k \sin (\theta+\pi / 3)-1]$ & $T[1+2 k \sin (\theta-\pi / 3)]$ \\
\hline & 4 & $T[2 k \sin \theta-1]$ & $2 k T \sin (\pi / 3-\theta)$ & $2 T[1-k \sin (\theta+\pi / 3)]$ \\
\hline \multirow{4}{*}{ B } & 1 & $2 k T \sin (\theta-\pi / 3)$ & $T[1-2 k \sin \theta]$ & $2 k T \sin (\theta+\pi / 3)$ \\
\hline & 2 & $T[2 k \sin (\theta+\pi / 3)-1]$ & $2 k T \sin (\theta-\pi / 3)$ & $2 T[1-k \operatorname{sir} \varphi]$ \\
\hline & 3 & $T[1-2 k \sin (\theta+\pi / 3)]$ & $T[2 k \sin \theta-1]$ & $T[1-2 k \sin (\theta-\pi / 3)]$ \\
\hline & 4 & $2 T[1-k \sin \theta]$ & $2 k T \sin (\theta+\pi / 3)$ & $T[2 k \sin (\theta-\pi / 3)-:$ \\
\hline \multirow{4}{*}{$\Sigma$} & 1 & $2 k T \sin \theta$ & $T[1-2 k \sin (\theta-\pi / 3)]$ & $-2 k T \sin (\theta+\pi / 3)$ \\
\hline & 2 & $2 T[:-k \sin (\theta-\pi / 3)]$ & $-2 k T \sin (\theta+\pi / 3)$ & $T[2 k \sin \theta-1]$ \\
\hline & 3 & $T[1+2 k \sin (\theta+\pi / 3)]$ & $T[2 k \sin (\theta-\pi / 3)-1]$ & $T[1-2 k \sin \theta]$ \\
\hline & 4 & $-T\left[1+2 k \sin \left(\theta+\frac{\pi}{3}\right]\right.$ & $2 k T \sin \theta$ & $2 T[1-k \sin (\theta-\pi / 3)]$ \\
\hline \multirow{4}{*}{$\mathrm{J}$} & 1 & $-2 k T \sin \theta$ & $T[1+2 k \sin (\theta+\pi / 3)]$ & $2 k T \sin (\theta-\pi / 3)$ \\
\hline & 2 & $T[2 k \sin (\theta+\pi / 3)-1]$ & $-2 k T \sin \theta$ & $2 T[1+k \sin (\theta+\pi / 3)]$ \\
\hline & 3 & $T[1-2 k \sin (\theta-\pi / 3)]$ & $-T\left[1+2 k \sin \left(\theta+\frac{\pi}{3}\right]\right.$ & $T[1+2 k \sin \theta]$ \\
\hline & 4 & $2 T[:+k \sin (\theta+\pi / 3)]$ & $2 k T \sin (\theta-\pi(3)$ & $-T[:-2 k \sin \theta]$ \\
\hline \multirow{4}{*}{$\Xi$} & 1 & $-2 k T \sin (\theta+\pi / 3)$ & $T[1+2 k \sin \theta]$ & $2 k T \sin (\pi / 3-\theta)$ \\
\hline & 2 & $2 T[1+k \sin \theta]$ & $2 k T \sin (\pi / 3-\theta)$ & $-T\left[1+2 k \sin \left(\theta+\frac{\pi}{3}\right]\right.$ \\
\hline & 3 & $T[1+2 k \sin (\theta-\pi / 3)]$ & $-T[1+2 k \sin \theta]$ & $T[1+2 k \sin (\theta+\pi / 3)]$ \\
\hline & 4 & $T[2 k \sin (\theta-\pi / 3)-1]$ & $-2 k T \sin (\theta+\pi / 3)$ & $2 T[1+k \sin \theta]$ \\
\hline \multirow{4}{*}{$=$} & 1 & $2 k T \sin (\theta+\pi / 3)$ & $T[1+2 k \sin (\theta-\pi / 3)]$ & $-2 k T \sin \theta$ \\
\hline & 2 & $-T[1+2 k \sin \theta]$ & $2 k T \sin (\theta+\pi / 3)$ & $2 T[1+k \sin (\theta-\pi / 3)]$ \\
\hline & 3 & $T[1+2 k \sin \theta]$ & $T[2 k \sin (\pi / 3-\theta)-1]$ & $T[1-2 k \sin (\theta+\pi / 3)]$ \\
\hline & 4 & $2 T[1+k \sin (\theta-\pi / 3)]$ & $-2 k T \sin \theta$ & $-T\left[1+2 k \sin \left(\theta+\frac{l}{3}\right]\right.$ \\
\hline
\end{tabular}

The calculation results are as follows :

$$
t_{a}=T(1-2 k \sin \theta) \quad t_{b}=T\left[2 k \sin \left(\theta+\frac{\pi}{3}\right)-1\right] \quad t_{c}=T\left[2 k \sin \left(\theta-\frac{\pi}{3}\right)+1\right]
$$

Where $k=2 V / \sqrt{3}$, modulation amplitude $0 \leq k \leq 1$.

The duration of the voltage vectors corresponding to the apexes of the triangles B, C, and $\mathrm{D}$ can be calculated in the same way. 

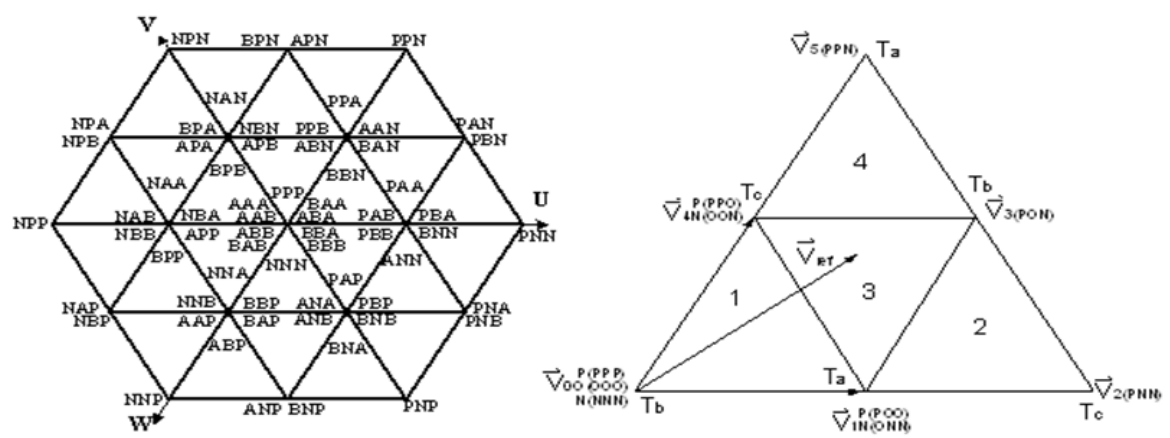

Figure 9. Space Voltage Vectors of Hybrid Clamp Topology Figure10. Space Voltage Vectors of Hybrid Clamp Topology

Table 5 shows the analytical time expressions for $t_{a} 、 t_{b}$ and $t_{c}$ in the regions in the six sectors. These time segments are then distributed in a certain sequence in the sample $\operatorname{period}\left(T_{s}\right)$ so that the PWM wave is symmetrical and the neutral point voltage remains balanced.

Referring to Figure 7, and using the space vector PWM technique, generally, three voltage vectors corresponding to the apexes of the triangle that includes the reference voltage vector are selected to minimize the harmonic components of output line-to-line voltage. The duration of these three voltage vectors is obtained as Table 6 . Figure 11 The turn on and turn off sequence and it's last time.

Table 6. Algorithm of Optimal Vector and Pulse Sequence

\begin{tabular}{|c|c|c|c|c|c|}
\hline State & Condition & $\begin{array}{c}\text { A } \\
\text { phase }\end{array}$ & $\begin{array}{c}\mathrm{B} \\
\text { phase }\end{array}$ & $\begin{array}{c}\mathrm{C} \\
\text { phase }\end{array}$ & Pulse sequence \\
\hline \multirow{8}{*}{$V_{c d 1}>V_{c d 2}$} & $\begin{array}{c}V_{X 1}<V_{c d 1} V_{X 2}<V_{c d 1} \\
V_{X 3}<V_{c d 1}\end{array}$ & $\begin{array}{l}\mathrm{B} \\
\text { vector }\end{array}$ & $\begin{array}{l}\mathrm{B} \\
\text { vector }\end{array}$ & $\begin{array}{l}\mathrm{B} \\
\text { vector }\end{array}$ & $\begin{array}{c}{[\mathrm{B} N \mathrm{~N} \mathrm{~N}][\mathrm{B} B \mathrm{~B}]} \\
{[\mathrm{P} \text { B N][P B B }][\mathrm{P} \mathrm{P}} \\
\text { B] }\end{array}$ \\
\hline & $\begin{array}{c}V_{X 1}<V_{c d 1} V_{X 2}<V_{c d 1} \\
V_{X 3}>V_{c d 1}\end{array}$ & $\begin{array}{c}\mathrm{B} \\
\text { vector }\end{array}$ & $\begin{array}{l}\mathrm{B} \\
\text { vector }\end{array}$ & $\begin{array}{c}\mathrm{A} \\
\text { vector }\end{array}$ & $\begin{array}{c}{[\mathrm{B} N \mathrm{~N}][\mathrm{B} \text { B N }]} \\
{[\mathrm{P} \text { B N]][P B A][P P }} \\
\mathrm{A}]\end{array}$ \\
\hline & $\begin{array}{c}V_{X 1}<V_{c d 1} \quad V_{X 2}>V_{c d 1} \\
V_{X 3}<V_{c d 1}\end{array}$ & $\begin{array}{c}\mathrm{B} \\
\text { vector }\end{array}$ & $\begin{array}{c}\text { A } \\
\text { vector }\end{array}$ & $\begin{array}{c}\mathrm{A} \\
\text { vector }\end{array}$ & $\begin{array}{c}{[\mathrm{B} \text { N N][B A N] }} \\
{[\mathrm{B} A \mathrm{~A} A][\mathrm{P} A \mathrm{~A}][\mathrm{P} \text { P }} \\
\text { A] }\end{array}$ \\
\hline & $\begin{array}{c}V_{X 1}<V_{c d 1} V_{X 2}>V_{c d 1} \\
V_{X 3}>V_{c d 1}\end{array}$ & $\begin{array}{c}\mathrm{B} \\
\text { vector }\end{array}$ & $\begin{array}{c}\text { A } \\
\text { vector }\end{array}$ & $\begin{array}{c}\text { A } \\
\text { vector }\end{array}$ & $\begin{array}{c}{[\mathrm{B} \text { N N][B A N] }} \\
{[\mathrm{B} \text { A A }][\mathrm{P} A \mathrm{~A}][\mathrm{P} \text { P }} \\
\mathrm{A}]\end{array}$ \\
\hline & $\begin{array}{c}V_{x 1}>V_{c d 1} V_{x 2}<V_{c d 1} \\
V_{x 3}<V_{c d 1}\end{array}$ & $\begin{array}{c}\mathrm{A} \\
\text { vector }\end{array}$ & $\begin{array}{c}\mathrm{B} \\
\text { vector }\end{array}$ & $\begin{array}{c}\mathrm{B} \\
\text { vector }\end{array}$ & $\begin{array}{c}{[\mathrm{A} \mathrm{N} \mathrm{N}][\mathrm{A} \mathrm{B} \mathrm{N}]} \\
{[\mathrm{P} \text { B N][P B B] }][\mathrm{P} \mathrm{P}} \\
\mathrm{B}]\end{array}$ \\
\hline & $\begin{array}{c}V_{X 1}>V_{c d 1} V_{X 2}<V_{c d 1} \\
V_{X 3}>V_{c d 1}\end{array}$ & $\begin{array}{c}\mathrm{A} \\
\text { vector }\end{array}$ & $\begin{array}{l}\mathrm{B} \\
\text { vector }\end{array}$ & $\begin{array}{c}\mathrm{A} \\
\text { vector }\end{array}$ & $\begin{array}{c}{[\mathrm{A} N \mathrm{~N}][\mathrm{A} \text { B N }]} \\
{[\mathrm{P} \text { B N][P B A][P P }} \\
\mathrm{A}]\end{array}$ \\
\hline & $\begin{array}{c}V_{x 1}>V_{c d 1} V_{X 2}>V_{c d 1} \\
V_{x 3}<V_{c d 1}\end{array}$ & $\begin{array}{c}\text { A } \\
\text { vector }\end{array}$ & $\begin{array}{c}\text { A } \\
\text { vector }\end{array}$ & $\begin{array}{l}\mathrm{B} \\
\text { vector }\end{array}$ & $\begin{array}{c}{[\mathrm{A} N \mathrm{~N} N][\mathrm{A} A \mathrm{~A} \text { N] }} \\
{[\mathrm{P} \text { A N][P A B][P P }} \\
\text { B] }]\end{array}$ \\
\hline & $\begin{array}{c}V_{X 1}>V_{c d 1} V_{X 2}>V_{c d 1} \\
V_{X 3}>V_{c d 1}\end{array}$ & $\begin{array}{c}\text { A } \\
\text { vector }\end{array}$ & $\begin{array}{c}\text { A } \\
\text { vector }\end{array}$ & $\begin{array}{c}\text { A } \\
\text { vector }\end{array}$ & 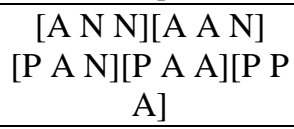 \\
\hline$V_{c d 1}<V_{c d 2}$ & - & $\begin{array}{c}\text { A } \\
\text { vector }\end{array}$ & $\begin{array}{c}\text { A } \\
\text { vector }\end{array}$ & $\begin{array}{c}\mathrm{A} \\
\text { vector }\end{array}$ & 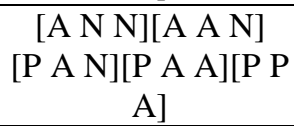 \\
\hline
\end{tabular}



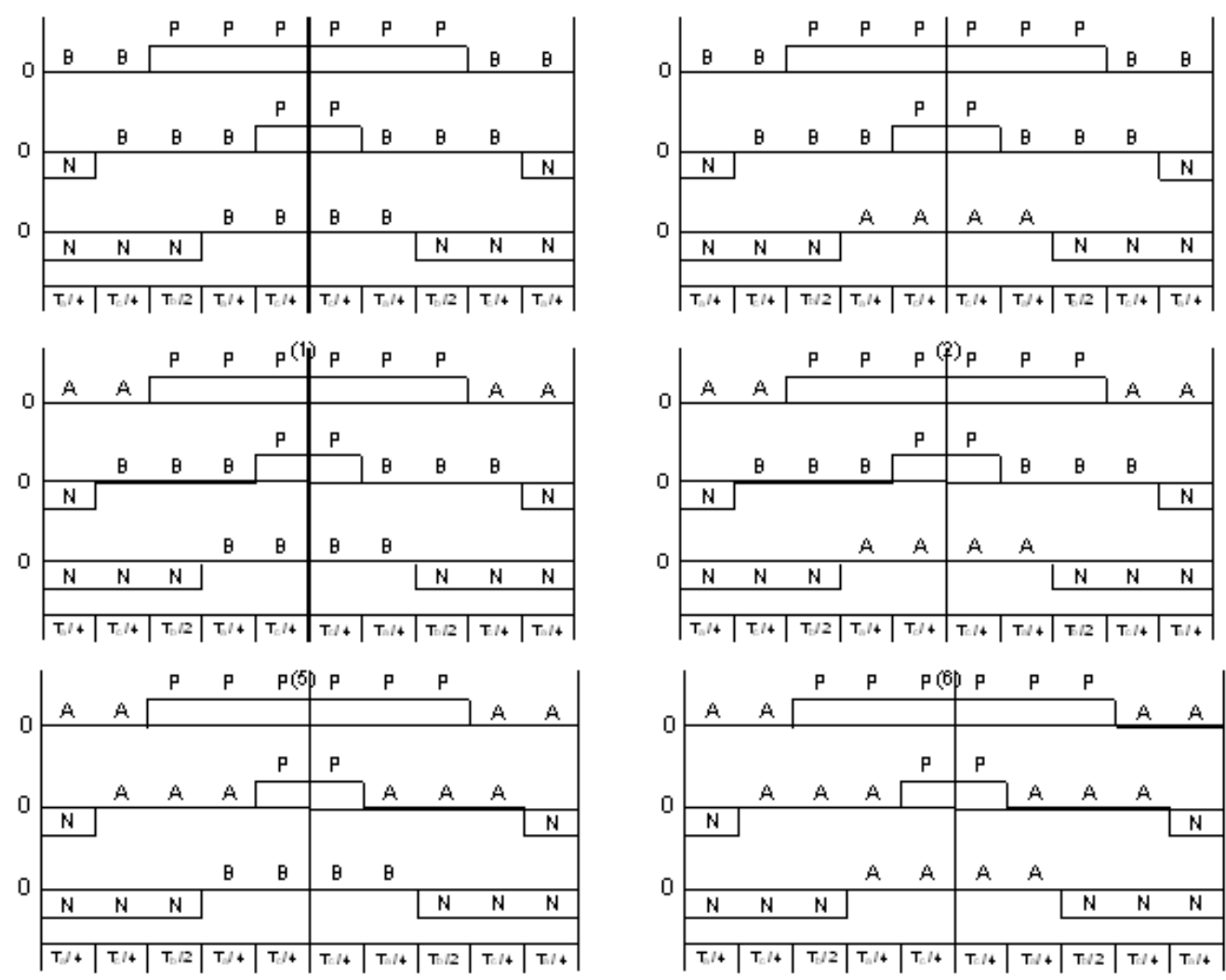

(7)

(8)

Figure 11. The Turn on and Turn off Sequence and It's La

\section{Simulation and Experimental Results}

Figure 12 is the simulation waveform of phase Voltage Ua and line voltage Uab in switch mode according to the space vector algorithm of the hybrid clamped three level converter. Figure13 is the simulation waveform of 3-phase output currents.

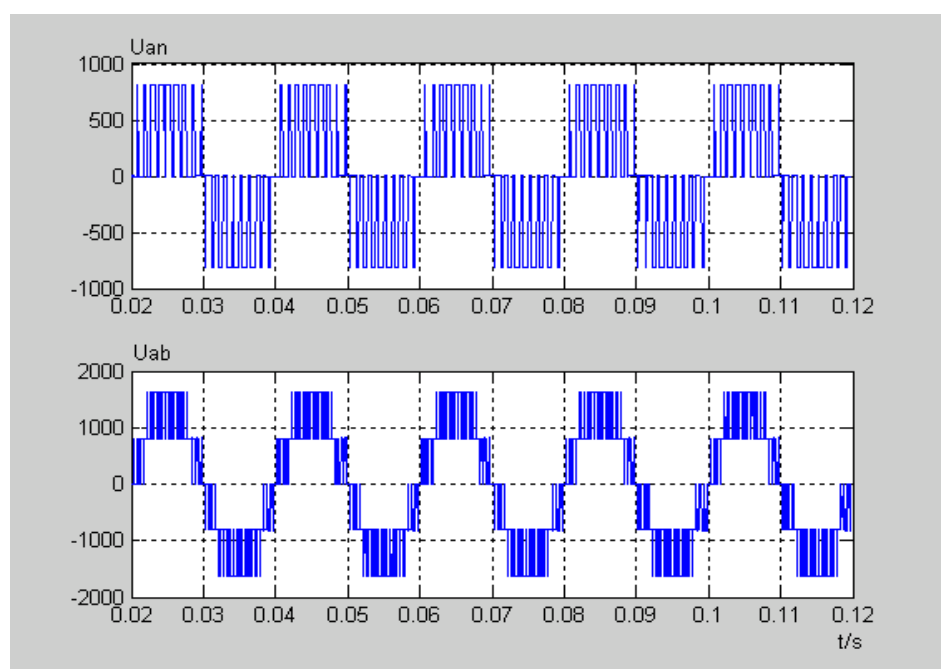

Figure 12. The Simulation Waveform of Phase Voltage Ua and Line Voltage Uab in Switch Mode 


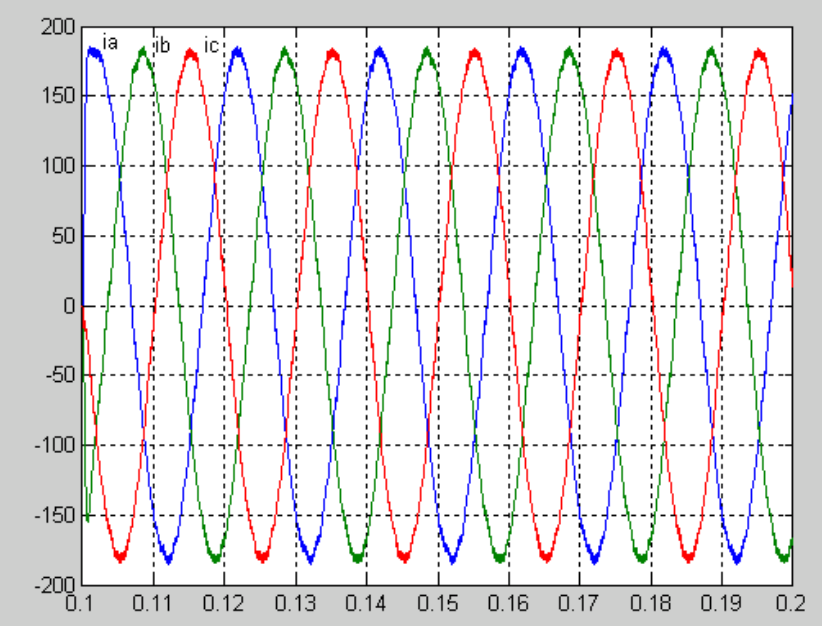

\section{Figure 13. The Simulation Waveform of 3-Phase Output Currents}

In order to validate the proposed hybrid clamped three level converter topology and space vector PWM algorithm, a dual PWM three-level converter was constructed in the laboratory. Figure 14 shows a block diagram of how the balancing algorithm was implemented. The modulation is programmed in 1 \# DSP+CPLD which generates desired switching states of rectifier, 2 \# DSP+CPLD achieved desired switching states of inverter, as described above, this information along with the desired switching state forms the address of the desired state in the redundant state selection Table 6.

The flying capacitor was set to $470 u F / 450 \mathrm{~V}$. A $2.2 \mathrm{~kW}$ induction motor of $1460 \mathrm{rad} / \mathrm{min}$ with the same parameter in steady-state study was used as a load. The dc voltage was supplied from an isolated rectified three-phase source. All the other operation conditions are the same as in the three-level steady state simulation study. As can be seen, the voltages and currents exhibit typical three-level inverter performance.

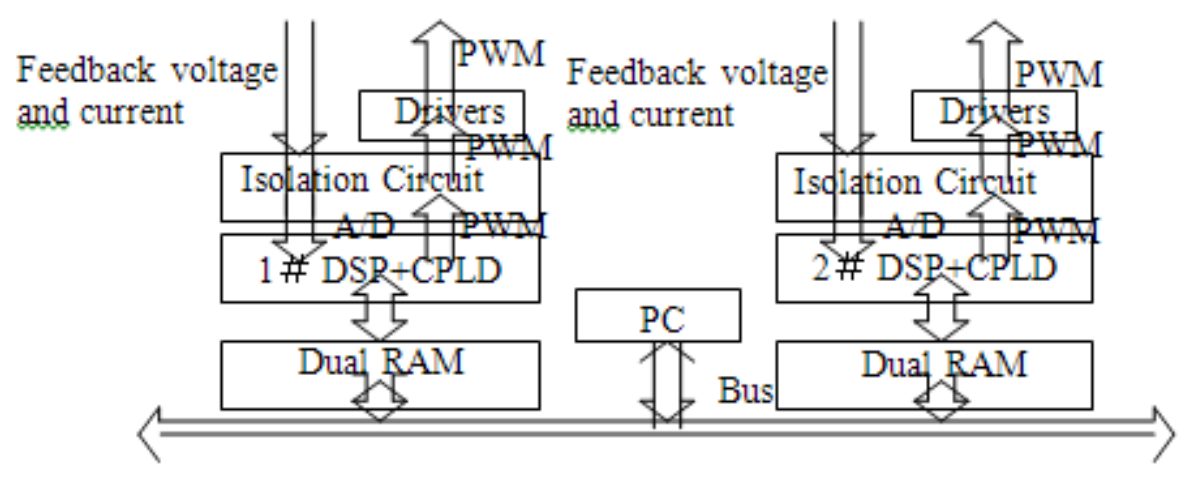

Figure 14. Control System of Dual Pwm Hybrid Clamp Topology 


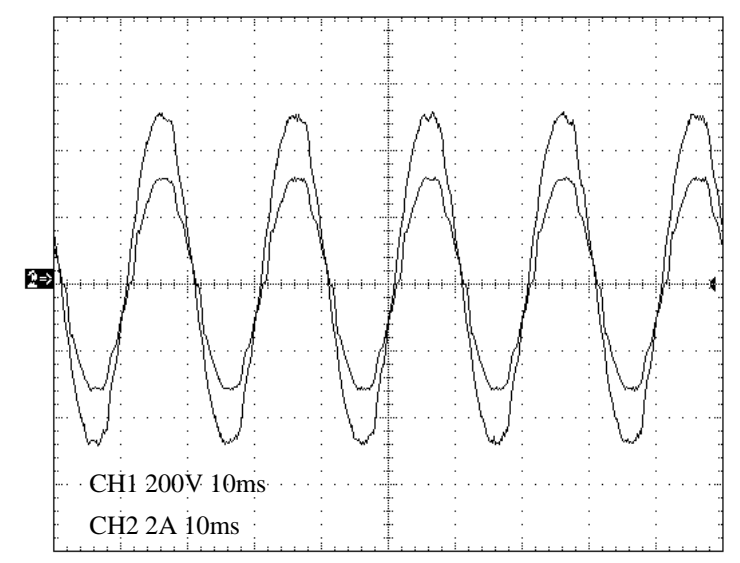

Figure 15. Single Input Voltage and Current Wave in Rectifier

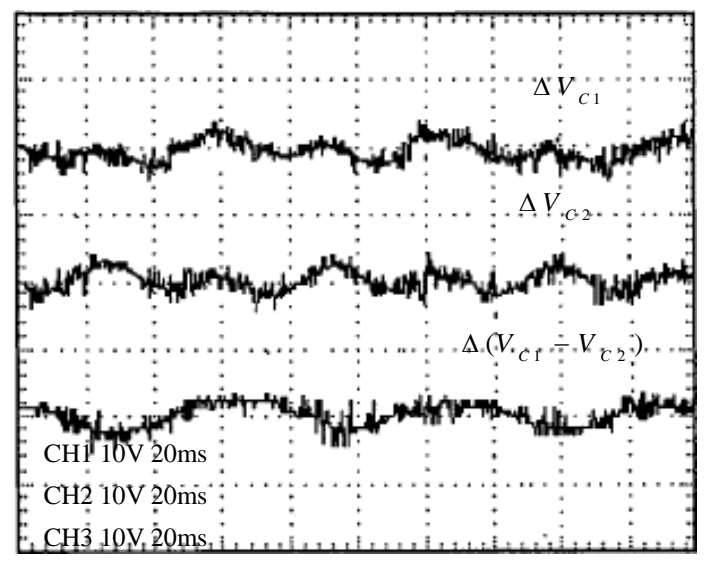

Figure 16. Voltage Error between Dual Dc Capacitor

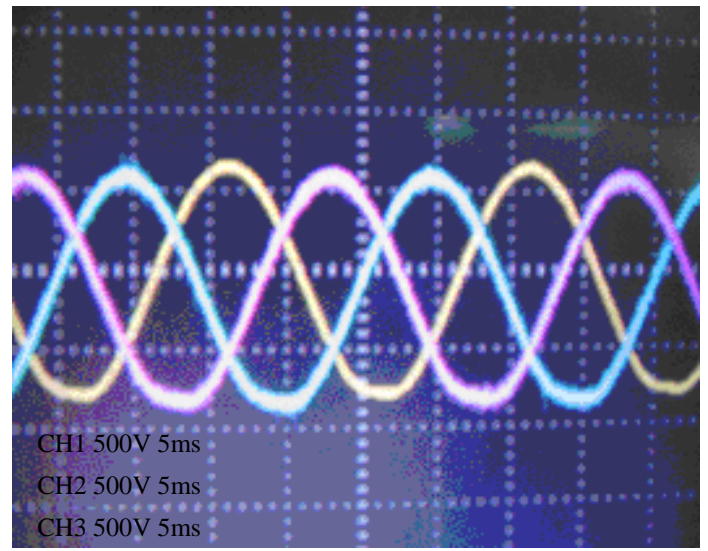

Figure 17. Three Phase Output Voltage in Inverter 


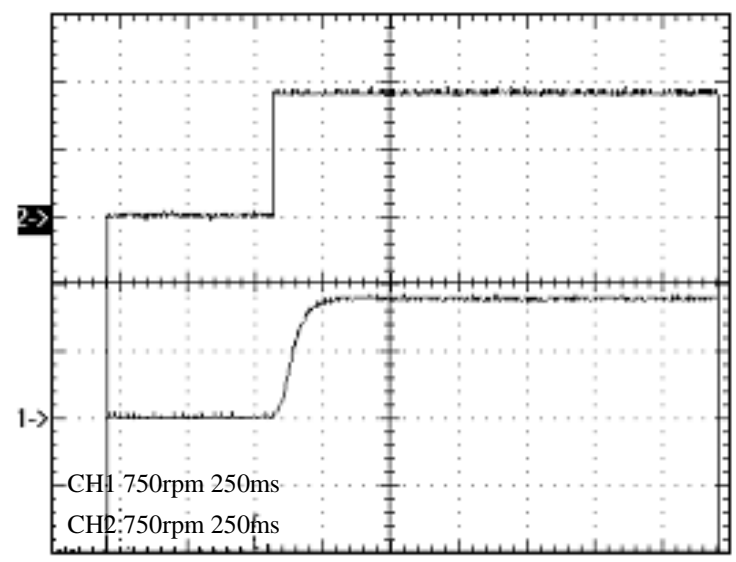

Figure 18. Ch1: Speed Response Sign Ch2: Speed Given Sign

The Figure 16 shows the wave of difference of capacitor voltage in DC side, It can achieve the balancing demand of DC side capacitor voltage because the neutral point voltage distortion becomes small, The Figure 17 shows output voltage wave of inverter which The low frequency harmonics seen in the current waveform. The Figure18 shows that motor have can be achieved rapid dynamic response with the speed given sign. It is verified that the algorithm mentioned in this paper is accurate by simulation and experimentation results.

\section{Acknowledgements}

This paper focuses its researches on dual-PWM three-level hybrid clamped converters and the novel space vector PWM Algorithm. Theory analysis, simulation and experimentation were made to investigate its character. A novel hybrid clamped dualPWM three-level circuit topology was discussed, Analyzed the work principle of this converters and built up the mathematical model of the converter, The switching states of hybrid clamped three-level converters increase to sixty-four from twenty-seven switching states of diode clamp three-level converters. In order to realize optimization of its redundant voltage space vectors by detecting voltage of clamped capacitor and difference of capacitor voltage in DC side. This system was simulated by Matlab, In the last, the control circuit and main circuit was designed with DSP and CPLD, The simulation and experimentation results proved it was very effective and practicability.

\section{References}

[1] T. Opetuk, I. Zolo and G. Dukic, "Greening elements in the distribution networks", Journal of Industrial Engineering and Management, vol. 3, no. 2, (2010), pp. 353-369.

[2] X. Wang, L. Jiang and L. Shu, "Profit allocation in fuzzy cooperative games in manufacturing and logistics industry”, Journal of Industrial Engineering and Management, vol. 7, no. 2, (2014), pp. 448460.

[3] P. Hammond, "A new approach to enhance power quality for medium voltage ac drives", IEEE Transaction Industry Applications, vol. 33, no. 1, (1997), pp. 202-208.

[4] J. Rodríguez, J.-S. Lai and F. Z. Peng, "Multilevel Inverters: A Survey of Topologies, Controls, and Applications", IEEE Transactions On Industrial Electronics, vol. 49, no. 4, (2002), pp. 724737.

[5] E. P. Wiechmann, P. Aqueveque, R. Burgos and J. Rodríguez, "On the efficiency of voltage source and current source inverters for high power drives", IEEE Trans. Ind. Electron, vol. 55, no. 4, (2008), pp. 1771-1782.

[6] D. Zhong, L. M. Tolbert and J. N. Chiasson, "Active harmonic elimination for multilevel converters", IEEE Transaction on power electronics, vol. 21, no. 2, (2006), pp. 459-469.

[7] A. Hodder, J. J. Simond and A. Schwery, "Unbalanced DC-Link voltage regulation in a back-toback 3-level PWM converter for a double-fed induction motor-generator", IEEE Proceedings Electric Power Applications, vol. 152, no. 6, (2005), pp. 1477-1481.

[8] Z. Pan and F. Z. Peng, "Voltage balancing control of diode-clamped multilevel rectifier/inverter 
systems”, IEEE Transactions On Industry applications, vol. 41, no. 6, (2005), pp. 1698-1706.

[9] B.-R. Lin and C.-H. Huang, "Three-phase capacitor-clamped converter with fewer switches for use in power factor correction", IEEE Transactions on electronic power Application, vol. 152, no. 3, (2005), pp. 141-148.

[10] L. Xu and V. G. Agelidis, "Active capacitor voltage control of flying capacitor multilevel converters", IEEE Transactions on electronic power Application, vol. 151, no. 3, (2004), pp. 313-320.

[11] I.-D. Kim, E.-C. Nho, H.-G. Kim and J. S. Ko, "A generalized Undeland snubber for flying capacitor multilevel inverter and converter", IEEE Transactions on Industrial Electronics, vol. 51, no. 6, (2004), pp. 1290-1296.

[12] D.-W. Kang, W.-K. Lee and D.-S. Hyun, "Carrier-rotation strategy for voltage balancing in flying capacitor multilevel inverter", IEEE Transactions on electronic power Application, vol. 151, no. 2, (2004), pp. 239-248.

[13] L. M. Tolbert, F. Z. Peng and T. G. Habetler, "Multilevel PWM methods at low modulation indices", IEEE Trans Power Electronics, vol. 15, no. 4, (2000), pp. 719-725.

[14] T. A. Meynard and H. Foch, "Multi-level choppers for high voltage applications", Eur. Power Electron, vol. 2, no. 1, (1992), pp. 41-44.

[15] P. W. Hammond, "A new approach to enhance power quality for medium voltage AC drives", IEEE Trans. Ind. Applicat., vol. 33, no. 2, (1997) January/February, pp. 202-208.

[16] J. de Leon Morales, M. F. Escalante and M. T. Mata-Jimenez, "Observer for DC voltages in a cascaded H-bridge multilevel STATCOM", IET Electric Power Applications, vol. 1, no. 6, (2007), pp. $79-889$.

[17] J. Rodriguez, J.-S. Lai and F Z. Peng, "Multilevel inverters: a survey of topologies, controls, and applications", IEEE Transactions on Industrial Electronics, vol. 49, no. 4, (2002), pp. 724738.

[18] M. D. Manjrekar, P. K. Steimer and T. A. Lipo, "Hybrid multilevel power conversion system: a competitive solution for high-power applications", IEEE Trans. Ind. Appl., vol. 36, no. 3, (2000), pp. $834-841$.

[19] B. L. Ben and S. Tadakuma, "A novel multilevel carrier-based PWM-control method for GTO inverter in low index modulation region", IEEE Transaction Industry Application, vol. 42, no. 1, (2006), pp. 121-127.

[20] N. V. Nho and M. J. Youn, "Comprehensive study on space-vector-PWM and carrier-basedPWM correlation in multilevel invertors", IEE Proceedings Electric Power Applications, vol. 153, no. 1, (2006), pp. $149-158$.

[21] J. O. P. Pinto and B. K. Bose, "A Stator Flux Oriented Vector Controlled Induction Motor Drive with Space-Vector PWM and Flux-Vector Synthesis By Neural Network", IEEE Tran. Industry Application, vol. 37, no. 5, (2001), pp. 1308-1318.

[22] S. R. Bowes and Y. S. Lai, "The relationship between space-vector modulation and regularsampled PWM", IEEE Tran. Power Electronics, vol. 14, no. 9, (1997), pp. 670-679.

[23] V. Blasko, "Analysis of a hybrid PWM based on modified space-vector and triangle-comparison method", IEEE Tran. Industry Application, vol. 33, no. 3, (1997), pp. 756-764.

[24] K. Zhou and D. Wang, "Relationship Between Space Vector Modulation and Three-Phase Carrier-Based PWM: A Comprehensive Analysis", IEEE Tran. Industry Electronics, vol. 49, no. 1, (2002), pp. 186-196.

This work was supported by Key Disciplines of Beijing Municipal Commission of Education under (20081D0501700204) and Funding Project of Beijing Municipal Commission (KM201010016011)

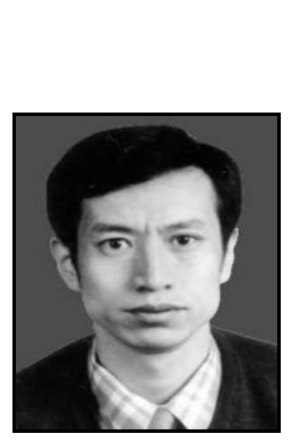

\section{Author}

Yue Yuntao, was Received the M.Sc. and Ph.D. degrees from China University of Mining and Technology-Beijing in 2007. During 2009 and 2012, he was a postdoctoral Researcher with School of Automation, Beijing University of Aeronautics and Astronautics. Currently he is electrical engineering department director of Beijing University Of Civil Engineering And Architecture. He has extensive consulting experiment in power electrical and power drives. 
International Journal of Hybrid Information Technology Vol.8, No.6 (2015) 